\title{
O PAPEL DOS NITS NA RELAÇÃO UNIVERSIDADE-EMPRESA: CARACTERÍSTICAS E DESAFIOS ${ }^{1}$
}

Julia Paranhos, professora Adjunta; Grupo de Economia da Inovação do Instituto de Economia/UFRJ (juliaparanhos@ie.ufrj.br)

Bruna Cataldo, bolsista do GEI/IE/UFRJ e aluna de mestrado da Faculdade de Economia/UFF (brunaccandrade@gmail.com)

Ana Carolina Andrade, INMETRO e aluna de doutorado PPED/IE/UFRJ (an.carolina@ gmail.com)

\section{RESUMO:}

Em 2004, o estabelecimento da Lei de Inovação no Brasil levou à obrigatoriedade de criação de Núcleos de Inovação Tecnológica (NITs) nas instituições públicas de pesquisa. Seu papel seria a promoção e facilitação da relação entre instituições científicas e tecnológicas (ICTs) e empresas. Desde então diversos NITs foram criados e outros, já existentes, reestruturados (ARCHILA, 2015; PARANHOS, 2012). O objetivo neste trabalho é apresentar o marco institucional e de apoio ao estabelecimento dos NITs, assim como, a configuração e características dos hoje existentes no Brasil, discutir os obstáculos ainda presentes ao seu funcionamento e especular sobre possíveis aprendizados para as políticas públicas de promoção da relação universidade-empresa. Para isso, é feito um levantamento das leis, das políticas industriais e de ciência e tecnologia e dos programas de apoio à criação e estruturação dos NITs. Além disso, são analisados os resultados do Formulário para Informações sobre a Política de Propriedade Intelectual das ICTs, de 2007 a 2015, à luz dos resultados de uma pesquisa de campo realizada em 2015 e da literatura sobre o tema. Conclui-se que, apesar do crescimento do número de NITs por todo o país, os desafios à sua atuação ainda são enormes e não há, hoje, políticas ou ações governamentais que estejam focando estes desafios.

\section{Palavras-chave: Relação universidade-empresa, Núcleos de Inovação Tecnológica, Brasil.}

\begin{abstract}
:
In 2004, the Innovation Law was enacted in Brazil and made it mandatory for public research institutions to create Technology Transfer Offices (TTO). Its role would be the promotion and facilitation of the relationship between scientific and technological institutions and industry. Since then, several TTOs have been created and others, already established, restructured (ARCHILA, 2015; PARANHOS, 2012). The objective of this paper is to present the TTO's institutional framework, the structure developed to support their establishment and the characteristics of the existing TTOs in Brazil. After that, it will be discussed the obstacles to their functioning and the possible learnings to public policies to promote university-industry interaction. In order to do that, the laws, industrial and science and technology policies, and the funding programs to support the creation and structuring of the TTOs were analyzed. Moreover, the results from the Ministry of Science, Technology and Innovation survey on TTOs (Formict, in Portuguese), from 2007 to 2015, were examined in the light of the field research that took place in 2015 and the literature. It is possible to conclude that despite the growth in the number of TTOs throughout the country, the challenges to their functioning are still big and there are no policies or government actions focused in solving them.
\end{abstract}

Key words: University-Industry Interaction, Technology Transfer Offices (TTO), Brazil.

Área 6 - Políticas públicas e regulação

6.2 Políticas de Ciência, Tecnologia e Inovação

JEL: O, O32, 038.

${ }^{1}$ Pesquisa financiada pelo edital CNPq 41/2013. 


\section{INTRODUÇÃO}

Ao longo dos últimos 30 anos, houve uma mudança significativa nos sistemas de propriedade intelectual (PI). Orsi e Coriat (2006) alegam que o novo sistema de PI ampliou os limites de proteção intelectual, eliminando a diferença entre invenção e descoberta, e permitiu a apropriação privada da ciência básica. Os autores ressaltam, porém, que esta apropriação pode atrapalhar o desenvolvimento da inovação, por impedir o fluxo natural de novas pesquisas sobre bases de conhecimento comuns. O estabelecimento deste sistema, no entanto, foi realizado em conjunto com um movimento, iniciado nos EUA a partir do Bayh-Dole Act, 1984, de introdução de mecanismos para a apropriação do conhecimento produzido em ICTs. Alguns autores discutem que os custos transacionais gerados pela proteção do conhecimento das ICTs poderiam ser desnecessários, enquanto outros afirmam que a falta desta poderia dificultar o estímulo à transferência de tecnologia em instituições científicas (Etzkowitz \& Leydesdorff, 2000). Outra questão importante levantada na literatura é que a interação com empresas pode atrapalhar a missão das universidades e institutos de pesquisa, e a solução sugerida é a criação de políticas que estimulem a interação entre ICTs e empresas sem interferir na liberdade científica das ICTs (Rosenberg \& Nelson, 1994; Welsh et al, 2008).

Para que a melhor estruturação seja possível, deve-se estudar as características principais da relação universidade-empresa. De Fuentes e Dutrénit (2012) observaram que são três os fatores principais que afetam essa relação, sendo eles: estímulo para a interação, canais de interação e os resultados auferidos. Entre os canais de interação, os autores sugerem que os mais relevantes para o estabelecimento de relacionamentos de longo prazo entre ICTs e empresas são o licenciamento de propriedade industrial, o desenvolvimento conjunto de projetos e a absorção pelas empresas de recursos humanos advindos da universidade. D'Este e Patel (2007) fizeram um mapeamento dos canais de interação, para além do licenciamento de tecnologia, mais importantes na relação entre ICTs e empresas e concluíram que os mais frequentes eram reuniões e conferências, consultoria e contratos, desenvolvimento conjunto de projetos, treinamento e criação de novas infraestruturas, como spin-offs. Dentre esses resultados, pode-se observar que muitos dos canais de interação mais eficientes para a interação são (ou podem ser) objeto de atuação dos Núcleos de Inovação Tecnológica (NITs) ${ }^{2}$.

Bozeman et al. (2014) analisam algumas atividades de instituições científicas e tecnológicas (ICTs) dos EUA e seu impacto na transferência de tecnologia. Os autores apresentam que o número de licenciamentos de ICTs para empresas está positivamente relacionado ao momento de criação dos escritórios de transferência de tecnologia (ETT) e ao aumento dos níveis de financiamento das atividades de pesquisa e desenvolvimento (P\&D). Além disso, identificaram que o tamanho dos ETTs está relacionado ao tamanho das receitas provenientes de licenciamento de tecnologias, ao aumento de financiamento de $\mathrm{P} \& \mathrm{D}$ e à geração de spin-offs.

Ao analisar as atividades dos ETTs e suas implicações para políticas relacionadas, Siegel et al. (2007) sugerem que as universidades devem adotar estratégias de comercialização de tecnologia, estabelecendo prioridades e os objetivos de longo prazo da interação com empresas. Essa estratégia deve incluir: (i) a alocação de recursos para facilitar o licenciamento, dado que o estágio da pesquisa afeta o interesse das empresas, pois, quanto mais avançado o estágio, menor o risco percebido pela indústria; (ii) os modos adotados de comercialização, escolhendo entre licenciamento, cessão, criação de spin-offs, ou desenvolvimento conjunto de projetos tecnológicos; e (iii) áreas técnicas disponíveis para a interação, dado que há diferença no escopo e na profundidade da pesquisa em diferentes campos da ciência em cada instituição.

\footnotetext{
${ }^{2}$ A partir da Lei de Inovação (10.973) de 2004, os escritórios de transferência de tecnologia ou outros departamentos que tratassem da relação universidade-empresa nas ICTs passaram a ser chamados de NITs. Neste artigo, os dois termos serão usados alternadamente, em geral, ETT para os estudos estrangeiros e NIT para os nacionais.
} 
Os autores identificam ainda algumas boas práticas para os ETTs: boa redação de patentes para proteção dos interesses das ICTs no momento da comercialização, sistemas de recompensa para os pesquisadores envolvidos em interação com empresas, e manutenção da equipe dos ETTs para evitar a perda de habilidades específicas relacionadas à interação com empresas e às particularidades institucionais da ICT (Siegel et al., 2007). Reforçando esse argumento, em outro trabalho, Siegel et al. (2003) coloca que a produtividade dos ETTs é, em grande parte, dependente de fatores institucionais e do contexto em que a instituição está inserida, daí a grande variabilidade de performance destes nos estudos relacionados ao tema. As práticas que mais afetam a relação entre ICTs e empresas são as práticas organizacionais para gestão da PI, de recompensa dos pesquisadores e da equipe dos ETTs e a capacidade de diminuir barreiras culturais e de informação entre ICTs e empresas. Os autores entendem que os ETTs funcionam como fontes interculturais para garantir o atendimento de expectativas tanto dos pesquisadores quanto das empresas e, por isso, equipes de ETTs formadas por uma mistura de cientistas e pessoas com experiência em empresas são mais eficientes do que as equipes formadas por cientistas e advogados.

Muscio (2010) estudou os fatores que afetam o acesso aos ETTs de universidades italianas pelos pesquisadores, e concluiu que seus objetivos primários eram: difusão da cultura empreendedora, apoio à criação e ao desenvolvimento de spin-offs, e valorização econômica dos resultados acadêmicos. Ele concluiu ainda que (i) departamentos de pesquisa que mais interagem com a indústria são também os que mais acessam os ETTs, (ii) departamentos chefiados por gerentes com menor tempo de chefia tendem a acessar mais conhecimentos dos ETTs, buscando mais segurança para a interação, (iii) o trabalho dos ETTs é mais atraente para departamentos que desenvolvem pesquisa com menor aplicabilidade industrial, (iv) e que as universidades mais conceituadas em pesquisa científica são as que mais utilizam seus ETTs. Ele chama atenção para o fato de que a legitimidade dos ETTs é importante, dado que a percepção dos pesquisadores sobre os benefícios de acessar esses Escritórios é essencial para o sucesso da transferência de tecnologia, dado que os ETTs, em geral, não têm condições ou a equipe necessária para buscar em cada laboratório as pesquisas viáveis para comercialização.

Sobre a construção de legitimidade nos ETTs, O'Kane et al. (2015) trazem a percepção de que eles trabalham com dois princípios distintos: o dos pesquisadores e o das empresas, o que muitas vezes pode levar a uma dificuldade de estabelecer uma identidade única própria. Eles sugerem que os ETTs devem buscar mostrar neutralidade na sua função de intermediários e criar uma missão própria, em grande parte distinta da missão da instituição em que estão inseridos.

No Brasil, os NITs foram criados pela Lei da Inovação, em 2004, com a função inicial e primordial de zelar pelo conhecimento e a PI produzidos nas ICTs. Não foi a partir desta Lei que o movimento iniciou no país, alguns ETTs e departamentos para promoção de parcerias já existiam em várias ICTs, mas foi a partir da obrigatoriedade da Lei e o estabelecimento de políticas de promoção da inovação, que houve um fortalecimento e crescimento destes.

Desde o início dos anos 2000, as políticas industriais e tecnológicas brasileiras têm se pautado no fortalecimento das instituições de ensino e pesquisa, reforçando o papel das ICTs na promoção da inovação e do desenvolvimento econômico e social. Conforme afirma Sutz (2000), em países em desenvolvimento, grande parte da geração de conhecimento tecnológico está localizada em ICTs públicas, dado que as atividades de $\mathrm{P} \& \mathrm{D}$ desenvolvidas por empresas são baixas e há pouco foco no desenvolvimento interno de conhecimento como estratégia de competição. No caso do Brasil, o estabelecimento de relacionamento entre ICTs e empresas torna-se uma alternativa para o setor produtivo entrar em contato com o desenvolvimento (ou aquisição) de insumos intangíveis, importante para a geração de capacidade tecnológica, dados os baixos esforços inovativos da indústria nacional (RAPINI, 2007). 
No entanto, muitos desafios estão postos à cooperação entre ICTs e empresas como problemas relacionados à indefinição em questões relacionadas a direitos de PI, dificuldades de comunicação, entraves burocráticos, déficit de pessoal especializado para o desenvolvimento de pesquisa, falta de financiamento e culturas diferente nas ICTs e empresas em termos de atividades de P\&D. Contudo, dada a intensificação, a partir da década de 1980, dessas parcerias, há a necessidade de estabelecimento de mecanismos institucionais que respondam por essa interação para transferência de conhecimento e tecnologia (RAPINI, 2007). O estabelecimento dos NITs foi um destes mecanismos.

Liew et al. (2012) trazem informações sobre a preferência atual das empresas de adotar relações mais formais e sistemáticas com ICTs, ao invés de conduzir as negociações diretamente com os pesquisadores, especialmente no que toca a gestão de PI para as definições de divisão de rendimentos, responsabilidades de cada uma das partes e titularidade. $\mathrm{O}$ autor comenta que esses NITs podem desafogar as equipes de pesquisa da gestão das questões financeiras e legais relacionadas às interações universidade-empresa, e que esses Núcleos devem ser empoderados e ter pessoal treinado para avaliar e gerir melhor os valores de mercados dos projetos provenientes destas parcerias.

Castro e Souza (2012) conduziram um estudo com quatro dos maiores NITs brasileiros e sugerem que a atividade de patenteamento aumentou após sua institucionalização. Os autores observaram que a posição dos NITs na estrutura organizacional da ICT pode ajudar na sua legitimidade perante a comunidade científica da instituição, mas também pode ser um entrave à medida que os acordos devem ser chancelados pelas instâncias máximas dessas instituições, o que os coloca em posição de subordinação com pouca autonomia. Os entrevistados nesse trabalho citaram que a parceria com pesquisadores é de grande relevância e os interesses deles nos projetos devem ser considerados nas negociações com empresas. Um entrave mencionado foi a incapacidade dos NITs de prospectar empresas para a realização de acordos de licenciamento tecnológico, o que sugere que a demanda costuma partir das empresas ou dos próprios pesquisadores, que já trazem propostas de empresas que podem absorver a tecnologia desenvolvida. Essa seria uma das razões pelas quais as atividades de patenteamento são mais bem-sucedidas, no âmbito dos NITs, do que as atividades de transferência de tecnologia. Alguns NITs, no entanto, já demonstram preocupação com o patenteamento de certas criações, dado que também se faz necessário avaliar o potencial comercial das tecnologias, já incorporando a estratégia de transferência.

A partir deste contexto, os objetivos neste trabalho são apresentar o marco institucional e de apoio ao estabelecimento dos NITs, descrever a configuração e características dos NITs hoje existentes no Brasil, discutir os obstáculos presentes ao seu funcionamento e especular sobre possíveis aprendizados para as políticas públicas de promoção da relação universidade-empresa. Para isso, é feito um levantamento das leis, das políticas industriais e de C\&T e dos programas de apoio à criação e estruturação dos NITs. Também são analisados os resultados do Formulário para Informações sobre a Política de Propriedade Intelectual das ICTs (Formict), de 2007 a 2015, à luz dos resultados de uma pesquisa de campo realizada em 2015 e da literatura sobre o tema. $\mathrm{O}$ artigo está dividido em quatro seções, além desta Introdução e da Conclusão. Na primeira seção, é apresentada a metodologia do levantamento de dados. Na segunda seção, são apresentados o marco institucional e as políticas de criação e apoio aos NITs. Em sequência, são desenvolvidas as características dos NITs a partir dos dados do Fomict. Na quarta seção, os resultados são discutidos e analisados à luz da pesquisa de campo e da literatura.

\section{METODOLOGIA}

O estudo foi realizado em duas etapas. Na primeira, foi feito um levantamento das políticas, da legislação e dos instrumentos para a promoção da relação universidade-empresa no país entre 2003 a 2016 e qual o papel dos NITs definido nestes documentos. Analisou-se também a Lei 10.973/2004 
(Lei de Inovação), e as alterações trazidas pela Lei 13.243/2016, chamada de Marco de Ciência, Tecnologia e Inovação (Marco de CT\&I). Estudou-se ainda a Emenda Constitucional 85/2015, que precedeu a promulgação do Marco, implementando as modificações necessárias para o aprimoramento da lei na Constituição Federal. Foram ainda levantados os instrumentos de ação para estabelecimento e desenvolvimento dos NITs através dos editais de apoio de fundações de fomento: Conselho Nacional de Desenvolvimento Científico e Tecnológico (CNPq), Finep - Inovação e Pesquisa, e três Fundações de Amparo à Pesquisa (FAPs) dos estados do Rio de Janeiro, São Paulo e Minas Gerais, por serem estados com NITs de referência para o país, entre 2012 e 2016. Foram então descritos os recursos financeiros disponibilizados em termos de valor absoluto e por projeto, os itens financiáveis e não-financiáveis, a periodicidade de lançamento e outros itens associados. A pesquisa foi feita com as palavras-chave NIT, ICT, interação e inovação nas respectivas bases de editais.

Na segunda etapa, foram levantados, tratados e analisados os dados do Formict, que é respondido anualmente pelas ICTs sobre seus NITs ao Ministério de Ciência, Tecnologia e Inovação. Foram analisados os formulários de 2007 a $2015^{3}$. Utilizou-se as informações sobre as atividades das ICTs ligadas à promoção do relacionamento com empresas, as suas políticas de inovação, a implantação de NITs, a proteção do conhecimento e a transferência de tecnologia.

Para finalizar o entendimento sobre os NITs e a identificação de facilitadores e obstáculos ao seu fortalecimento, foram utilizados na análise os resultados de cinco entrevistas realizadas em 2015 sobre a visão sobre as parcerias, funcionamento do NIT, a atuação na interação e os contratos ativos com empresas. Os códigos utilizados para identificação dos entrevistados diz respeito à ordem de realização das entrevistas. Estas foram feitas com coordenadores e agentes de inovação dos NITs de uma universidade estadual, três universidades federais e uma universidade privada nos estados de São Paulo, Minas Gerais e Rio Grande do Sul. Todas as entrevistas foram presenciais, gravadas e baseadas em um roteiro com perguntas abertas. A realização da pesquisa de campo visa ampliar e aprofundar os conhecimentos de fatos recentes e complexos, conforme afirma Yin (2005).

\section{DESENVOLVIMENTO DO ESTUDO}

\subsection{Marco político e legal da relação universidade-empresa e instrumentos de promoção}

\subsubsection{Políticas Industriais e de C\&T}

A retomada das políticas industriais e de ciência e tecnologia no início dos anos 2000, no Brasil, é realizada tendo a promoção do relacionamento universidade-empresa como um dos seus pilares. Este processo inicia-se com a promulgação da Política Industrial, Tecnológica e de Comércio Exterior (PITCE) em 2003, com foco na melhoria da eficiência produtiva, aumento da capacidade inovativa de empresas nacionais e expansão das exportações, sendo a interação universidadeempresa apontada como fundamental para o processo. Buscava-se estruturar um Sistema Nacional de Inovação (SNI) capaz de articular os agentes do processo de inovação do setor produtivo - as empresas, centros de pesquisa, instituições de fomento ao desenvolvimento tecnológico, de apoio à metrologia, PI, gestão tecnológica e do conhecimento e instituições de apoio à difusão tecnológica (MCTI, 2003).

\footnotetext{
${ }^{3}$ Note que o questionário foi sendo modificado e ampliado durante os anos e, com isso, algumas respostas não compreendem todo o período mencionado, aparecendo apenas a partir do ano em que a nova pergunta foi inserida. Além disto, os dados disponíveis são agregados, não sendo possível realizar análise setorial. Para isto, seria necessário fazer levantamentos de dados primários individuais, modificando o escopo da análise.
} 
No âmbito da PITCE, foi estabelecida uma política de ciência e tecnologia (C\&T), o Programa de Aceleração do Crescimento de Ciência e Tecnologia (PAC de C\&T), que reforça a importância da interação entre empresas e ICTs e detalha de forma mais estruturada as ações necessárias para sua promoção, em especial, gerando orientações e estímulos para as ICTs do sistema de C\&T expandirem suas atividades com o sistema produtivo. Primeiramente, a formação e capacitação de recursos humanos para a área de CT\&I foi incentivada, tendo como uma das metas estimular a parceria entre ICTs e empresas através do "Programa Nacional de Pós-Doutorado da CAPES". Posteriormente, houve a criação do "Programa de Fomento ao Desenvolvimento Científico, Tecnológico e de Inovação" com o fim de apoiar a geração de conhecimento por meio de incentivo à pesquisa básica, aplicada e ao desenvolvimento tecnológico de novos produtos e processos. Também foi determinada a criação de um instrumento para estimular a criação e as atividades dos grupos de pesquisa, o programa " $\mathrm{CNPq}$ - Programa de Pesquisa Tecnológica ou de Inovação para Pequenas Empresas", que consistiu do lançamento de editais para realização de projetos de pesquisa em associação com pequenas empresas de base tecnológica. Foram apresentados programas setoriais cujas metas envolviam a promoção da interação entre empresas e ICTs (MCTI, 2007).

Em 2008, foi lançada uma nova política industrial, a Política de Desenvolvimento Produtivo (PDP), responsável pela manutenção do ciclo expansivo que o Brasil vivia à época por meio da superação de quatro desafios: ampliação da capacidade de oferta, controle do balanço de pagamentos, elevação da capacidade inovativa e fortalecimento de micro e pequenas empresas. Essa política não faz menções à promoção das parcerias entre o setor produtivo e ICTs (MDIC, 2008). Em 2011, uma nova política industrial é estabelecida, o Plano Brasil Maior (PBM), com o objetivo de apoiar o setor produtivo e melhorar sua competitividade de forma sustentável e inclusiva. A interação universidade-empresa é citada no "Plano Nacional de Plataformas de Conhecimento", cujos objetivos determinados foram a promoção da solução de problemas técnicos por meio da obtenção de produtos ou processos inovadores que envolvam risco tecnológico; e incentivo à parceria entre empresas e ICTs. Esse plano foi desenvolvido em articulação com políticas específicas para C\&T previstas na Estratégia Nacional de Ciência e Tecnologia (ENCT) (ABDI, 2013).

A ENCT, estabelecida em 2012, foi a política com maior foco nas parcerias entre ICTs e empresas do ponto de vista da criação de programas e instrumentos de incentivo, como o "Programa para Promoção da Inovação", que contou com uma iniciativa para ampliar a participação empresarial no desenvolvimento inovativo e criar a Empresa Brasileira de Pesquisa e Inovação Industrial (Embrapii), que tem como objetivo ampliar parcerias entre ICTs e empresas para acelerar o desenvolvimento tecnológico. Foi também apontada a necessidade de reformar as universidades, uma tendência internacional balizada pelo aumento da colaboração interinstitucional, mas foi reforçado que, o fomento à pesquisa e o aumento da dotação orçamentária das ICTs, apesar de importantes, não levam ao resultado desejado se forem esforços isolados.

Percebe-se, portanto, que a relação universidade-empresa vem sendo destaque nas políticas de CT\&I, havendo também reconhecimento nas políticas industriais, como uma atividade fundamental para o desenvolvimento industrial, tecnológico e inovativo do país. No entanto, esta sutil diferença reforça a ideia de que a interação universidade-empresa deve ser iniciada e orientada pela ICT, o que não está de acordo com o entendimento da abordagem sistêmica da inovação, que entende a ICT como parceira da empresa no processo inovativo. Neste sentido, o ator central que busca os parceiros para o desenvolvimento da inovação, deve ser a empresa (LUNDVALL, 2002; MOWERY \& SAMPAT, 2005)

\subsubsection{Marco legal}

Além das políticas industriais e de CT\&I, foi analisado o marco legal associado a elas para avaliar a evolução das práticas de interação universidade-empresa no Brasil e o papel do NIT dentro deste cenário. Sendo assim, nesta seção são apresentadas a Lei de Inovação e sua revisão, o Marco de 
CT\&I. A Lei de Inovação foi um dos marcos do retorno do foco governamental na promoção da indústria e da inovação. Uma das ações que impactou diretamente a promoção da interação universidade-empresa foi a determinação da criação obrigatória de NITs em todas as ICTs públicas do Brasil. Estes têm por finalidade facilitar e ampliar o relacionamento entre empresas e ICTs e avaliar a evolução das determinações jurídicas os envolvendo possibilita melhor avaliação do andamento deste objetivo.

A criação dos NITs foi determinada no artigo $2^{\circ}$ da Lei de Inovação, que definiu também as suas funções mínimas, sendo elas: a) zelar pela manutenção da política institucional de estímulo à proteção das criações, licenciamento, inovação e outras formas de transferência de tecnologia; b) avaliar e classificar os resultados decorrentes de atividades e projetos de pesquisa para o atendimento das disposições desta Lei; c) avaliar solicitação de inventor independente para adoção de invenção; d) opinar pela conveniência e promover a proteção das criações desenvolvidas na instituição; e) opinar quanto à conveniência de divulgação das criações desenvolvidas na instituição, passíveis de proteção intelectual; f) acompanhar o processamento dos pedidos e a manutenção dos títulos de PI da instituição (Lei 10.973/2004 apud PARANHOS, 2012, p. 115).

Apesar de ter iniciado o processo de incentivo à inovação e especificamente da interação universidade-empresa, a Lei apresentava limitações, em especial, em relação às medidas da Constituição, o que gerava insegurança jurídica na sua aplicação. Para resolver algumas destas questões foi iniciado um processo de aperfeiçoamento com a Emenda Constitucional 85 de 2015. Nesta foram promovidas modificações em artigos da Constituição Federal de 1988 a fim de inserir a inovação como objeto de ação, apoio e financiamento do Estado. O Quadro 1 indica as principais mudanças:

Quadro 1-Mudanças promovidas pela Emenda Constitucional 85

\begin{tabular}{|c|c|c|}
\hline Artigo & Original & Mudança \\
\hline Art. $23, \mathrm{~V}$ & $\begin{array}{l}\text { É competência comum da União, dos Estados, do Distrito Federal e dos } \\
\text { Municípios: proporcionar os meios de acesso à cultura, à educação e à } \\
\text { ciência }\end{array}$ & Insere tecnologia, pesquisa e inovação \\
\hline Art. 24, IX & $\begin{array}{l}\text { Compete à União, aos Estados e ao Distrito Federal legislar } \\
\text { concorrentemente sobre:educação, cultura, ensino e desporto }\end{array}$ & Insere ciência, tecnologia, pesquisa, desenvolvimento e inovação \\
\hline Art. $167 \S 5^{\circ}$ & Não existia & $\begin{array}{l}\text { Autoriza o remanejamento de recursos orçamentários em atividades de ciência, } \\
\text { tecnologia e inovação para viabilizar projetos mediante ato do Poder Executivo, } \\
\text { sem necessidade da prévia autorização legislativa }\end{array}$ \\
\hline Art. $200, \mathrm{~V}$ & $\begin{array}{l}\text { Ao sistema único de saúde compete, além de outras atribuições, nos } \\
\text { termos da lei: incrementar, em sua área de atuação, o desenvolvimento } \\
\text { científico e tecnológico }\end{array}$ & Insere inovação \\
\hline Art. $213, \S 2^{\circ}$ & $\begin{array}{l}\text { As atividades universitárias de pesquisa e extensão poderão receber apoio } \\
\text { financeiro do Poder Público }\end{array}$ & $\begin{array}{l}\text { Insere atividades de extensão, estímulo e fomento à inovação realizadas por } \\
\text { universidades e/ou por instituições de educação profissional e tecnológica }\end{array}$ \\
\hline Art. $218, \S 1^{\circ}$ & $\begin{array}{l}\text { O Estado promoverá e incentivará o desenvolvimento científico, a pesquisa } \\
\text { e a capacitação tecnológicas }\end{array}$ & $\begin{array}{l}\text { Determina tratamento prioritário para pesquisa básica e tecnológica, tendo em } \\
\text { vista a importância para o bem público e o progresso da ciência, tecnologia e } \\
\text { inovação }\end{array}$ \\
\hline Art. $218, \S 3^{\circ}$ & $\begin{array}{l}\text { O Estado apoiará a formação de recursos humanos nas áreas de ciência, } \\
\text { pesquisa e tecnologia, e concederá aos que delas se ocupem meios e } \\
\text { condições especiais de trabalho }\end{array}$ & $\begin{array}{l}\text { Insere inovação e incentivo por meio do apoio às atividades de extensão } \\
\text { tecnológica }\end{array}$ \\
\hline Art. $218, \S 6^{\circ}$ & Não existia & $\begin{array}{l}\text { Insere o estímulo à articulação entre entes, tanto públicos quanto privados, nas } \\
\text { diversas esferas de governo }\end{array}$ \\
\hline Art. $218, \S 7^{\circ}$ & Não existia & $\begin{array}{l}\text { Insere o incentivo à atuação no exterior das instituições públicas de ciência, } \\
\text { tecnologia e inovação }\end{array}$ \\
\hline $\begin{array}{l}\text { Art. 219, Parágrafo } \\
\text { único }\end{array}$ & Não existia & $\begin{array}{l}\text { Insere o estímulo à formação e ao fortalecimento da inovação nas empresas e } \\
\text { demais entes, à constituçãao e a manutenção de parques tecnológicos e demais } \\
\text { ambientes promotores da inovação, à atuação dos inventores independentes e à } \\
\text { criação, absorção, difusão e transferência de tecnologia }\end{array}$ \\
\hline Art. 219-A & Não existia & $\begin{array}{l}\text { Autoriza firmação de instrumentos de cooperação com órgãos e entidades } \\
\text { públicos e privados, inclusive para o compartilhamento de recursos humanos } \\
\text { especializados e capacidade instalada, para a execução de projetos de pesquisa, } \\
\text { de desenvolvimento científico e tecnológico e de inovação, mediante } \\
\text { contrapartida financeira ou não financeira }\end{array}$ \\
\hline Art. 219-B & Não existia & $\begin{array}{l}\text { O Sistema Nacional de será organizado em regime de colaboração entre entes, } \\
\text { tanto públicos quanto privados, com vistas a promover o desenvolvimento } \\
\text { científico e tecnológico e a inovação. }\end{array}$ \\
\hline
\end{tabular}

Fonte: Elaboração própria.

A partir dessa mudança, foi possível, então, iniciar as discussões para aprimoramento da Lei de Inovação. O resultado foi a promulgação do Marco de Ciência, Tecnologia e Inovação (2016), desenvolvido a partir de quatro objetivos: melhorar o acesso das empresas e ICTs privadas às 
políticas públicas de inovação; simplificar os procedimentos financeiros para CT\&I; melhorar a segurança jurídica; desenvolver um SNI com regras compatíveis em todos os níveis. O Quadro 2 consolida as mudanças.

\begin{tabular}{|c|c|}
\hline $\begin{array}{c}\text { Artigo - Lei de } \\
\text { Inovação }\end{array}$ & Aperfeiçoamento no Marco de CT\&I \\
\hline Art. $2^{\circ}$ & $\begin{array}{l}\text { Atualiza ou insere definições de: Criador; Incubadora de Empresas; Inovação; ICT; NIT; Fundação de Apoio; Pesquisador público; Parque tecnológico; Polo } \\
\text { Tecnológico; Extensão tecnológica; Bônus tecnológico; Capital intelectual. }\end{array}$ \\
\hline Art. $3^{\circ}$ & $\begin{array}{l}\text { Determina apoio às alianças estratégicas, aos projetos de cooperação e aos ambientes promotores de inovação; promove a atração de centros de P\&D de } \\
\text { empresas estrangeiras e sua interação com ICTs e empresas nacionais; determina a manutenção de programas para MPEs }\end{array}$ \\
\hline Art. $4^{\circ}$ & $\begin{array}{l}\text { Flexibiliza a atuação das ICTs públicas em projetos conjuntos nos quais há compartilhamento de seus recursos e capital intelectual mediante contrapartidas } \\
\text { financeiras e não financeiras }\end{array}$ \\
\hline Art. $5^{\circ}$ & $\begin{array}{l}\text { Autoriza a participação minoritária dos entes federados e suas entidades no capital social de empresas para o desenvolvimento de produtos ou processos } \\
\text { inovadores. A PI é de titularidade da empresa e a participação minoritária pode ser aceita como remuneração pela transferência de tecnologia e licenciamento }\end{array}$ \\
\hline Art. $6^{\circ}$ & Autoriza a ICT pública a celebrar contratos de transferência de tecnologia e licenciamento para outorga do direito de uso ou exploração de criação \\
\hline Art. $8^{\circ}$ & Possibilita a ICT prestar serviços técnicos para instituições públicas ou privadas \\
\hline Art. $9^{\circ}$ & $\begin{array}{l}\text { Faculta a celebração de parcerias por ICTs com instituições públicas ou privadas e reforça a isenção tributária das bolsas, com exceção de alunos de instituição } \\
\text { privada. Autoriza a concessão de recursos para execução de projetos às ICTs e aos pesquisadores compossibilidade de remanejamento }\end{array}$ \\
\hline Art. $10^{\circ}$ & $\begin{array}{l}\text { Autoriza a inclusão da previsão de recursos para despesas operacionais e administrativas nos instrumentos firmados com ICTs, empresas fundações de apoio, } \\
\text { agências de fomento e pesquisadores, }\end{array}$ \\
\hline Art. $11^{\circ}$ & Autoriza a ICT a ceder os direitos sobre criação ao criador ou a terceiro a título não oneroso \\
\hline Art. $13^{\circ}$ & Esclarece o conceito de ganho econômico sobre criação protegida \\
\hline Art.14 & $\begin{array}{l}\text { Garante a manutenção de gratificações específicas ao pesquisador público em outra ICT por conveniência da ICT de origem; permite o pesquisador público sob } \\
\text { regime de DE exercer atividades remuneradas de PD\&I observada a conveniência do seu órgão de origem. O Pesquisador pode ter ganhos adicionais }\end{array}$ \\
\hline Art. 15 & $\begin{array}{l}\text { Determina dever da ICT pública de instituir Política de Inovação: estratégicos, de empreendedorismo, para extensão tecnológica, para compartilhamento, de } \\
\text { gestão da PI e TT, para institucionalização e gestão do NIT, para capacitação de recursos humanos; para estabelecimento de parcerias }\end{array}$ \\
\hline Art. 16 & $\begin{array}{l}\text { Determina dever da ICT pública de ter um NIT próprio ou em associação com outras ICTs e fixa novas competências, permitindo que sejam entidades } \\
\text { juridicamente autônomas. Competências adicionais: desenvolver estudos de prospecção tecnológica e de inteligência competitiva no campo da PI, desenvolver } \\
\text { estudos para a transferência de inovação, promover e acompanhar parcerias da ICT comempresas; negociar e gerir os acordos de TT }\end{array}$ \\
\hline Art. 17 & Estabelece o dever de ICTs públicas e privadas beneficiadas pelo poder público de prestar informações ao MCTI \\
\hline Art. 18 & Possibilita Prever orçamento de royalties, serviços, etc. Captação de recursos pode ser feita através da Fundação de Apoio \\
\hline Art. 19 & $\begin{array}{l}\text { Determina o incentivo ao desenvolvimento de produtos, serviços e processos inovadores emempresas e entidades sem fins lucrativos mediante a concessão } \\
\text { de recursos para apoiar PD\&I de acordo com prioridades da política industrial. Subvenção pode ser aplicada a bens de capital desde que sejam voltados à } \\
\text { pesquisa financiada. }\end{array}$ \\
\hline Art. 20 & $\begin{array}{l}\text { Possibilita a contratação direta de ICTs, entidades privadas sem fins lucrativos ou empresas (isoladamente ou em consórcios) por entes do Poder Público para } \\
\text { a realização de PD\&I com risco tecnológico para a solução de problema técnico específico ou obtenção de produto, serviço ou processo inovador. }\end{array}$ \\
\hline Art. 22 & $\begin{array}{l}\text { Prevê apoio aos inventores independentes ao possibilitar que a ICT pública solicite a adoção de criação deste. Ao inventor fica garantido o poder de decisão } \\
\text { quanto à conveniência, oportunidade e elaboração do projeto mediante compromisso de compartilhamento de eventuais ganhos econômicos }\end{array}$ \\
\hline Art. 27 & $\begin{array}{l}\text { Inclui tratamento diferenciado às MPEs: simplificação e uniformização de procedimentos para gestão de CT\&I e do controle por resultados, promoção do } \\
\text { desenvolvimento e da difusão de tecnologias sociais e do fortalecimento da extensão tecnológica para inclusão produtiva e social. }\end{array}$ \\
\hline
\end{tabular}

Fonte: Elaboração própria.

Nota-se, portanto, que desde o retorno da preocupação governamental com a política industrial, houve um esforço para a criação e aprimoramento de um marco legislativo que permita o desenvolvimento tecnológico e inovativo do país. O que será posteriormente analisado é a eficácia deste marco regulatório na promoção dos NITs e a adequação às necessidades práticas destes no desenvolvimento de suas atividades.

\subsubsection{Instrumentos de promoção dos NITs}

Após a obrigatoriedade de criação dos NITs definida na Lei de Inovação, foram criados mecanismos de financiamento a sua criação e estruturação. Na esfera federal, Finep e CNPq foram os principais apoiadores, e no âmbito regional, as FAPs dos estados do Rio de Janeiro, São Paulo e Minas Gerais também se destacaram na criação de editais de apoio aos NITs das ICTs locais. Os detalhes destes editais são sistematizados abaixo. 
Quadro 3: Sistematização dos editais de apoio aos NITs (2006 a 2016).

\begin{tabular}{|c|c|c|c|c|c|c|}
\hline Instituição & Edital & $\begin{array}{c}\text { Valor Total } \\
(\mathbf{R} \$)\end{array}$ & \begin{tabular}{c|}
$\begin{array}{l}\text { Valor por } \\
\text { projeto }(\mathrm{R} \$)\end{array}$ \\
\end{tabular} & Despesas de Capital & Despesas de Custeio & Bolsas \\
\hline \multirow{2}{*}{ FINEP } & $\begin{array}{l}\text { CHAMADA PÚBLICA MCT/FINEP/Ação } \\
\text { Transversal - TIB (NIT) - 02/2006 }\end{array}$ & 8.000 .000 & 400.000 & $\begin{array}{l}\text { Material de consumo, soft wares, } \\
\text { manutenção de equipamentos, despesas } \\
\text { acessórias com importação, serviços de } \\
\text { terceiros, acesso a bases de dados, taxa de } \\
\text { inscriçăo em eventos }\end{array}$ & $\begin{array}{l}\text { Equipamento, material permanente e } \\
\text { bibliográfico, obras, instalaçôes civis e } \\
\text { reformas em geral }\end{array}$ & $\begin{array}{l}\text { Bolsas do CNPq segundo as regras e } \\
\text { procedimentos definidos por aquele órgão. }\end{array}$ \\
\hline & $\begin{array}{l}\text { CHAMADA PÚBLICA MCT/FINEP/ AÇ̃̃O } \\
\text { TRANSVERSAL - PRO-INOVA - 01/2008 }\end{array}$ & 3.500 .000 & $\mathrm{n} / \mathrm{a}$ & $\begin{array}{l}\text { Passagens, díríras, material de consumo, } \\
\text { serviços de terceiros }\end{array}$ & $\begin{array}{l}\text { Infra-estrutura, equipamentos e material } \\
\text { complementar } * 1\end{array}$ & $\begin{array}{l}\text { Bolsas tipo: Desenvolvimento Tecnológico } \\
\text { e Industrial (DTI); Iniciacãa Tecnológica e } \\
\text { Industrial (TTI); Especialista Visitante (EV) }\end{array}$ \\
\hline $\mathrm{CNPq}$ & $\begin{array}{l}\text { Chamada Pública MCT /SETEC/CNPq No } \\
\text { 92/2013*1 }\end{array}$ & 14.700 .000 & \begin{tabular}{|l|}
200.000 \\
300.000 \\
350.000
\end{tabular} & $\begin{array}{l}\text { Material de consumo, manutenção de } \\
\text { equipamentos, soft ware (licençaa } \\
\text { temporária), serviços de terceiros, despesas } \\
\text { acessórias, passagens/ diárias, participação } \\
\text { de membro da equipe na Reunião de } \\
\text { Acompanhamento e Avaliação (até RS } 4 \\
\text { mil) }\end{array}$ & Material bibliográfico; soft ware & $\begin{array}{l}\text { Bolsas tipo: Desenvolvimento Tecnológico } \\
\text { e Industrial (DTI); Especialista Visitante } \\
\text { (EV); ATP (Apoio Técnico em Extensão } \\
\text { no Pais) }\end{array}$ \\
\hline \multirow{3}{*}{ FAPEMIG } & EDIT AL FAPEMIG 09/2013 & 1.500 .000 & $\mathrm{n} / \mathrm{a}$ & \multicolumn{3}{|c|}{ 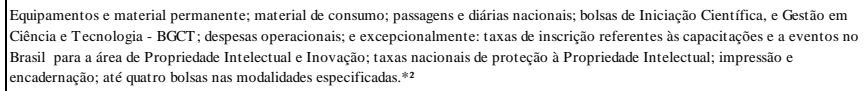 } \\
\hline & CHAMADA FAPEMIG 09/2014 & 1.500 .000 & 200.000 & \multicolumn{3}{|c|}{ 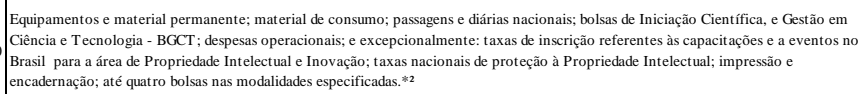 } \\
\hline & CHAMADA FAPEMIG 05/2016 & 1.000 .000 & 150.000 & \multicolumn{3}{|c|}{ 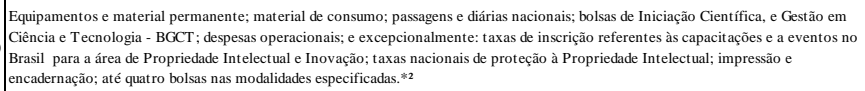 } \\
\hline \multirow{5}{*}{ FAPERJ } & Edital FAPERJ N. ${ }^{\circ} 11 / 2012$ & 1.000 .000 & 100.000 & $\begin{array}{l}\text { Aquisição de materiais permanentes e } \\
\text { equipamentos; obras de infraestrutura e } \\
\text { instalaçõos }\end{array}$ & \begin{tabular}{|l|} 
Serviços de terceiros; manutenção de \\
equipamentos e imóveis (até $5 \%$ do \\
custeio); diárias e passagens (até 5\% do \\
custeio, mas não para reuniôes científicas); \\
material de consumo; despesas de \\
importação (até $18 \%$ do valor do bem \\
importado)
\end{tabular} & n/a \\
\hline & Edital FAPERJ N. $.^{\circ} 11 / 2013$ & 1.000 .000 & 100.000 & $\begin{array}{l}\text { Aquisiç̃o de materiais permanentes e } \\
\text { equipamentos; obras de infraestrutura e } \\
\text { instalações }\end{array}$ & \begin{tabular}{|l|} 
Serviços de terceiros; manutenção de \\
equipamentos e imóveis (até $25 \%$ do \\
custeio); diárias e passagens (até 5\% do \\
custeio, mas não para reuniôes científicas); \\
material de consumo; despesas de \\
importação (até $18 \%$ do valor do bem \\
importado)
\end{tabular} & $\begin{array}{l}\text { Os proponentes de projetos aprovados } \\
\text { poderão solicitar uma bolsa de treinamento } \\
\text { e capacitacăão técnica (TCT) não renovável } \\
\text { e de duração máxima de } 12 \text { meses }\end{array}$ \\
\hline & \multirow{3}{*}{ Edital FAPERJ N. ${ }^{\circ} 08 / 2016$} & \multirow{3}{*}{2.000 .000} & 50.000 & \multirow{3}{*}{$\begin{array}{l}\text { Aquisiç̃ão de materiais permanentes e } \\
\text { equipamentos; obras de infraestrutura e } \\
\text { instalaç̧ôes }\end{array}$} & \multirow{3}{*}{$\begin{array}{l}\text { Serviços de terceiros; manutenção de } \\
\text { equipamentos e imóveis (até } 5 \% \text { do } \\
\text { custeio); diárias e passagens (até 5\% do } \\
\text { custeio, mas não para reuniôes científicas); } \\
\text { material de consumo; despesas de } \\
\text { importação (até } 18 \% \text { do valor do bem } \\
\text { importado) }\end{array}$} & \multirow{3}{*}{$\begin{array}{l}\text { Os proponentes de projetos aprovados } \\
\text { poderão solicitar uma bolsa de treinamento } \\
\text { e capacitacãão técnica (TCT) não renovável } \\
\text { e de duração máxima de } 12 \text { meses }\end{array}$} \\
\hline & & & 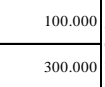 & & & \\
\hline & & & 300.000 & & & \\
\hline
\end{tabular}

*1 O valor máximo por projeto está separado, respectivamente, em: implementação de NIT s, capacitação de NIT s e implementação de arranjos de NIT

*2 Não há separação do tipo de gastos, são definidos apenas como itens financiáveis

A FAPESP não foi incluída por apresentar um programa contínuo de apoio aos NIT s, o PAPI

Fonte: Elaboração própria com base nas chamadas públicas disponíveis no sítio eletrônico das agências de fomento listadas.

O primeiro edital lançado pela FINEP, já em 2006, teve como objetivo selecionar propostas de apoio financeiro a projetos de criação e fortalecimento de NITs nas ICTs. O segundo, favorecido pela experiência anterior, apresenta algumas diferenças importantes. O edital, lançado em 2008, teve como objetivo selecionar propostas para apoio financeiro para capacitação dos NITs na gestão da política de inovação das ICTs e apoiar a promoção de eventos e iniciativas que difundam a inovação como instrumento para melhorar a competitividade. Diferente do primeiro, houve divisão dos projetos em linhas de modo a ter um tratamento diferenciado entre ICTs que pretendiam implantar um NIT e outras que já haviam passado dessa fase e buscavam consolidá-los. O segundo edital aumenta em R\$ 3 milhões o valor total do edital de 2006 e muda os detalhes de itens financiáveis, conforme descrito no Quadro 3. Outro diferencial do edital de 2008 é a inclusão de passagens e diárias, representando o reconhecimento que a participação em eventos e reuniões é fundamental, o que é defendido principalmente do ponto de vista da capacitação de pessoal. Nota-se também que as bolsas foram mais especificadas, podendo ser usado um máximo de $40 \%$ do valor do projeto nas modalidades Desenvolvimento Tecnológico e Industrial (DTI); Iniciação 
Tecnológica e Industrial (ITI); e Especialista Visitante (EV), entendendo que tais bolsas são essenciais para a constituição dos NITs ${ }^{4}$.

A chamada do $\mathrm{CNPq}$, cinco anos após o segundo edital da Finep, apresenta um valor global de R\$ 14.700.00,00, subdivido nas categorias de estruturação, consolidação e implantação e consolidação de arranjos de NITs, para ser executado em dois anos. As bolsas, nas modalidades DTI, EV e Apoio Técnico em Extensão no País, poderiam ter participação máxima de 50\% do orçamento disponível. A ICT teria a obrigação de gastar no mínimo $20 \%$ dos recursos com capacitação.

A partir de 2012, foi possível identificar editais de apoio aos NITs nas FAPs estaduais. A FAPEMIG tem três editais $(2013,2014$ e 2016), todos com estrutura distinta da dos entes federais, mas a mesma entre si. São pouco detalhados, com poucas especificações, não havendo diferenciação entre despesas correntes e capitais, consequentemente sem uma proporção a ser gasta com cada categoria, o que permite grande flexibilidade para os NITs usarem os recursos de acordo com suas necessidades. Os dois primeiros são iguais em toda a sua formulação, sendo o de 2014 apenas uma nova rodada de apoio financeiro para criação, estruturação, manutenção e capacitação das equipes dos NITs. Os valores globais são menores do que os federais, mas também incluem bolsas que auxiliam na formação das equipes - bolsas nas modalidades de Iniciação Científica e Tecnológica e Gestão em Ciência e Tecnologia e taxas de inscrição referentes às capacitações e a eventos realizados no Brasil para a área de Propriedade Intelectual e Inovação, importantes para capacitação das equipes.

Na FAPERJ, foram identificados quatro editais (2012, 2013, 2014 e 2016). Todos foram novas rodadas de financiamento do mesmo edital e parte do Programa de Apoio à Criação e Implementação de NIT no Estado do Rio de Janeiro. Os valores totais ficam em torno de R \$ 1 milhão, mas exige-se uma proporção de gastos de $50 \%$ para custeio e $50 \%$ para capital, o que dificulta o aproveitamento dos recursos pelos NITs já criados e que precisam de apoio para sua estruturação e desenvolvimento. Permite-se pagamento de diárias e passagens, mas excluindo participação em reuniões científicas; um limitante para a capacitação da equipe. A diferença do edital de 2014 foi a concessão de uma bolsa de treinamento e capacitação técnica (TCT) não renovável e de até 12 meses e o fim da proporção de gastos entre custeio e capital.

O edital de 2016 já foi lançado com estrutura um pouco diferente, apesar de ainda ser o mesmo programa. $\mathrm{O}$ valor global foi de $\mathrm{R} \$ 2$ milhões com a divisão em três estágios de desenvolvimento dos NITs: em fase de projeto, em implantação e em operação ou rede de NITs. Os recursos são parcelados em duas vezes, com a segunda parcela a ser liberada um ano depois do início do projeto e condicionada à aprovação de um relatório técnico parcial. A forma de solicitação de bolsas também foi modificada. Cada projeto pode solicitar três bolsas TCT de forma explícita nas propostas, com planos de trabalho específicos, mas sem essas serem computadas no valor final do projeto. Mesmo com algumas flexibilidades incluídas, percebe-se uma diferença para a FAPEMIG, que publica editais abertos e mais flexíveis. A FAPERJ desenvolve modelos de editais semelhantes aos do CNPq do ponto de vista de especificidade, detalhamento e limitações de uso dos recursos.

Por fim, a FAPESP apresenta um programa voltado para inovação e que contempla a estruturação de NITs desde o ano 2000, portanto antes da obrigatoriedade estipulada pela Lei de Inovação. Este é chamado Programa de Apoio à Propriedade Intelectual e foi criado por conta da percepção da necessidade de proteger a PI e licenciar os direitos sobre os resultados de pesquisas financiadas pela FAPESP. Suas atividades são executadas pelo Núcleo de Patenteamento e Licenciamento de Tecnologia, que foi criado com o fim de apoiar o registro e licenciamento de direitos de PI.

\footnotetext{
${ }^{4}$ As bolsas continuam a ser importantes formas de atração de pessoal para os NITs, mas dado que são válidas durante o período de execução do projeto, acabam gerando grande rotatividade de pessoal.
} 
É separado em duas modalidades: de capacitação e institucional. A primeira promove o apoio à melhoria do conhecimentos técnico-científicos dos NITs de São Paulo por meio do financiamento de estudos e intercâmbio em instituições estrangeiras com reconhecimento na área de transferência de tecnologia. Após essa primeira fase, os NITs poderão submeter projetos de pesquisa nas áreas de gestão, valoração e transferência de tecnologias. Na modalidade Institucional, ICTs de São Paulo recebem apoio através do registro e licenciamento de PI criado a partir dos resultados de pesquisas financiadas pela FAPESP. São Paulo apresenta, portanto, o instrumento de ação mais diferente em comparação aos outros estados e aos entes federais. O programa tem caráter contínuo, prevê um período prévio de capacitação de pessoal e, somente depois, de desenvolvimento de projetos sem estipulação de editais fixos determinando valores e/ou formas de utilização dos recursos.

\subsection{Caracterização dos NITs em operação no Brasil}

A partir da promulgação da Lei de Inovação, cresce de forma estável o número de NITs no Brasil, tendo atingido 264 ao final de 2014. São maioria entre as instituições da esfera federal e públicas (Gráfico 1) e localizadas, principalmente, no Sudeste, Sul e Nordeste (Gráfico 2). Ainda assim, cerca de $10 \%$ das ICTs que respondem ao Formict não têm seus NITs instalados e cerca de $20 \%$ estão com os NITs em fase de implementação. Isto significa que mesmo passados 13 anos da implementação da Lei de Inovação, muitas ICTs ainda não conseguiram instalar seus NITs, implementar sua política de inovação e organizar-se no sentido da promoção da transferência de tecnologia e interação com o setor produtivo.

Gráfico 1: Número de NITs por natureza jurídica da instituição

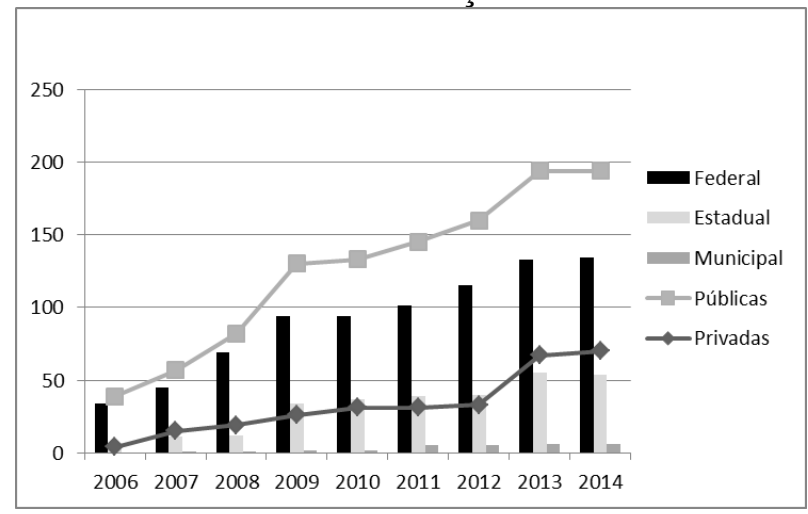

Fonte: Elaboração própria a partir de dados dos relatórios MCTI (2007 a 2015)
Gráfico 2: Distribuição regional das ICTs respondentes

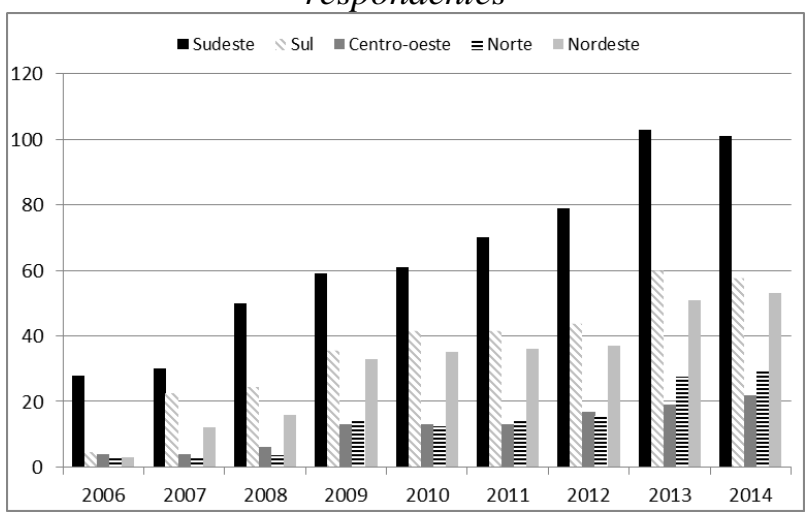

Fonte: Elaboração própria a partir de dados dos relatórios MCTI (2007 a 2015)

Os NITs ganham importância nas ICTs, mas sua estruturação ainda é difícil. Conforme mostra o Gráfico 3, o número de funcionários médio dos NITs é baixo (cerca de 8 funcionários). Há maioria de servidores, mas a participação de bolsistas, estagiários e terceirizados também é grande, o que gera muita rotatividade e dificuldade de retenção de mão de obra qualificada. Nota-se também uma troca de tipo de vínculo da mão-de-obra entre estagiários e bolsistas a partir de 2010. 


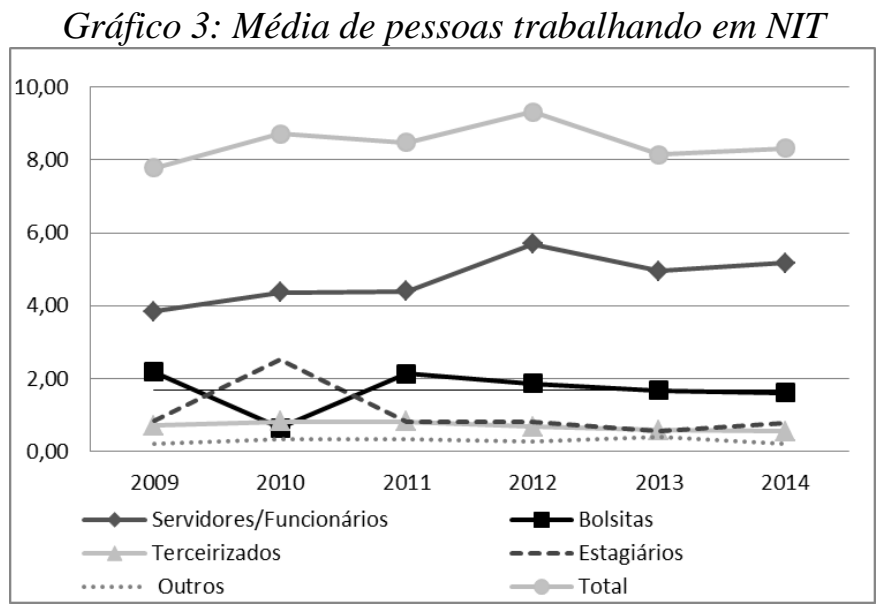

Fonte: Elaboração própria a partir de dados dos relatórios MCTI (2007 a 2015)

É significativo o número de ICTs com suas políticas de inovação implementadas, que já chega a 200. As demais, estão com a implementação em curso ou ainda não foram implementadas. A política de inovação consiste em uma documentação institucional formal que contenha as diretrizes gerais para a atuação em ações ligadas à inovação, à proteção da PI ${ }^{5} \mathrm{e}$ à transferência de tecnologia. $\mathrm{O}$ fato de a grande maioria ter avançado neste item já demonstra a atuação dos NITs nestas ICTs pois, apesar da obrigatoriedade da implementação destas políticas só ter sido introduzida no Marco de CT\&I, desde 2004 os NITs já são reconhecidos por lei como os responsáveis pela gestão das políticas de inovação nas ICTs.

Nota-se nos dados, o destaque de certas atividades nas políticas de inovação das ICTs: desenvolvimento de projetos de cooperação com terceiros, confidencialidade e acordos de parcerias estão presentes em cerca de $90 \%$ dos casos. Ganharam importância durante os anos, com o aumento da incidência em um maior número de ICTs, as atividades de ensino em temas correlacionados à inovação, alianças estratégicas, contratos prevendo a titularidade da PI e participação nos resultados e prestação de serviços, passando de $70 \%$ para $80 \%$.

Percebe-se, no entanto, que pouco mudou em termos do padrão de frequência de incidência das atividades mencionadas nas políticas de inovação das ICTs, a não ser pela atividade de compartilhamento de instalações, que teve um crescimento abrupto em 2011. É importante notar também que as atividades mais comuns estão relacionadas ao estabelecimento de parcerias com terceiros (empresas ou outras ICTs), e as atividades menos frequentes são as relacionadas aos pesquisadores/criadores.

A ampliação do estabelecimento dos NITs e das políticas de inovação nas ICTs muda o patamar e a dinâmica da gestão da PI, elevando também o número de Instituições com depósito de pedidos de proteção de PI. Eram 94 ICTs em 2009 e 161 em 2015 (61\% da amostra), um crescimento de mais de $71 \%$. Cresce em $66 \%$ o número de ICTs que não possuem pedido de proteção, mas cresceu em $69 \%$ a amostra de ICTs respondentes do Formict, o que demonstra que o crescimento tanto das ICTs com e sem pedidos de PI está influenciado pelo crescimento da amostra. Se considerarmos que a Lei de Inovação foi introduzida em 2004, e que seu principal foco no que tange as diretrizes de atuação dos NITs é a de zelar pela proteção do conhecimento das ICTs, ainda é alto o número de ICTs que não possui pedido de proteção de PI.

Ressalta-se, porém, que o número de depósitos não é suficiente para a análise da capacidade de interação e transbordamento das ICTs, é importante considerar a capacidade de transferência de

\footnotetext{
${ }^{5}$ Não há levantamento de dados sobre a evolução de pedidos de patentes de modo geral no Brasil, de modo que seria necessária a realização de uma pesquisa de maior proporção para conseguir esta informação.
} 
tecnologia ${ }^{6}$, e neste quesito os resultados ainda são muito incipientes. Conforme apontado no Gráfico 4, a grande maioria das ICTs (216) respondeu não possuir contratos de transferência de tecnologia. Cresceu menos de 30\%, entre 2010 (ano que a pergunta foi incluída no questionário) e 2014, o número em ICTs com contratos de transferência de tecnologia. Em 2014, estas ICTs representaram $22 \%$ (48) do total das ICTs da amostra.

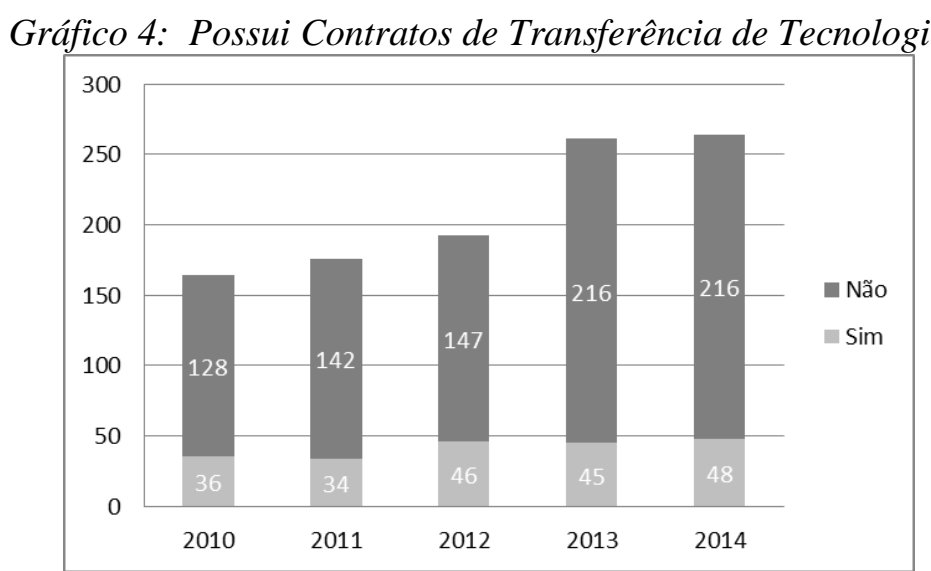

Fonte: Elaboração própria a partir de dados dos relatórios MCTI (2007 a 2015).

Tais contratos renderam em média $\mathrm{R} \$ 7$ milhões de reais para cada ICT em 2014, dado o valor total de $\mathrm{R} \$ 338,5$ milhões, apresentado na Tabela 1. Estes valores tiveram um crescimento bastante significativo durante o período analisado, cerca de $68 \%$ em relação a 2007 , quanto o total foi de R\$ 4,95 milhões. Em 2010, percebe-se uma mudança de patamar nos valores destes contratos, que alcançam R\$ 500 milhões em 2012, com participação importante das outras formas ${ }^{7}$ de transferência de tecnologia (84\%), um resultado atípico em relação a todos os outros anos. Em relação aos contratos, os sem exclusividade historicamente apresentam valores mais elevados do que os com exclusividade. Contratos de tecnologia com exclusividade referem-se àquelas negociações em que a ICT não pode negociar a mesma tecnologia com outras empresas, enquanto que os sem exclusividade permitem negociação da tecnologia com mais de uma empresa.

Tabela 1: Distribuição, de acordo com a exclusividade, dos contratos de tecnologia em ICTs (em milhões de reais).

\begin{tabular}{lcccccccc} 
& 2007 & 2008 & 2009 & 2010 & 2011 & 2012 & 2013 & 2014 \\
\hline $\begin{array}{l}\text { Com } \\
\text { exclusividade }\end{array}$ & 3,3 & 4,5 & 13,67 & 6,81 & 4,78 & 65,37 & 116 & 103,79 \\
\hline $\begin{array}{l}\text { Sem } \\
\text { exclusividade }\end{array}$ & 1,07 & 0,93 & 50,5 & 79,99 & 186,2 & 163,86 & 150,72 & 112,72 \\
\hline $\begin{array}{l}\text { Outras } \\
\text { formas }\end{array}$ & 0,58 & 7,73 & 3,28 & 104,17 & 27,6 & 271,61 & 35,99 & 121,95 \\
\hline Total & 4,95 & 13,16 & 67,45 & 190,97 & 218,58 & 500,84 & 302,71 & 338,46 \\
\hline
\end{tabular}

\footnotetext{
${ }^{6} \mathrm{O}$ termo transferência de tecnologia é utilizado de forma abrangente, incluindo tanto contratos de licenciamento ou cessão de direitos de PI, acordos de parceria de pesquisa, desenvolvimento e inovação, acordos de transferência de material biológico, como contratos ou convênio de permissão de utilização de laboratórios, equipamentos, instrumentos, materiais e instalações por empresas nacionais e organizações de direito privado sem fins lucrativos voltadas para atividades de pesquisa (MCTI, 2007 a 2015).

${ }^{7}$ Os contratos indicados como "outras formas" são aqueles que não envolvem tecnologia submetida a qualquer tipo de proteção.
} 
Valor médio

dos contratos

por ICT

$\mathrm{n} / \mathrm{a}$

$\mathrm{n} / \mathrm{a}$

$\mathrm{n} / \mathrm{a}$

5,30

6,43

10,89

6,73

7,05

Fonte: Elaboração própria a partir de dados dos relatórios MCTI (2007 a 2015).

\section{DISCUSSÃO DOS RESULTADOS COM BASE NAS ENTREVISTAS}

Como forma de ampliar o entendimento do papel dos NITs na relação universidade-empresa, foram realizadas entrevistas com coordenadores e agentes de inovação de cinco NITs distribuídos entre as regiões Sudeste e Sul, as duas regiões com maior concentração de NITs, conforme os dados apresentados na seção 3.2. Buscou-se variar a amostra em termos de natureza jurídica, incluindo ICTs públicas, federais e estaduais, e privadas. No entanto, nenhum padrão de características específicas foi identificado entre os tipos de natureza jurídica das ICTs. O que se pode perceber entre os NITs entrevistados são diferenças de características entre os mais antigos e mais recentes, ou seja, de acordo com seu tempo de funcionamento. NITs mais antigos estão mais estruturados, melhor inseridos na ICT, possuem maior número de pessoal e melhor capacitação.

A partir das evidências primárias identificadas na pesquisa de campo, foi possível levantar conclusões e hipóteses sobre os resultados apresentados na seção 3, pois foi possível ter um melhor entendimento e aprofundamento sobre a realidade e os desafios impostos aos NITs.

Todas as entrevistadas acham importante a definição de criação dos NITs pela Lei de Inovação para o fortalecimento das parcerias entre empresas e ICTs. O forte crescimento do número de ICTs com NIT é, sem dúvida, um resultado da imposição da Lei, mas também do espraiamento do entendimento da importância da estruturação das ICTs para essas parcerias. Isto fica evidente ao ver-se o crescimento de NITs nas ICTs privadas (que não são obrigadas por Lei), nos dados do Formict, e na estruturação do NIT da ICT privada que participou da pesquisa de campo. No entanto, ressaltou-se que as dificuldades enfrentadas para o estabelecimento e funcionamento dos NITs ainda são enormes. O dado de que $30 \%$ das ICTs ainda estão sem o NIT estruturado ou em estruturação, reforça a posição das entrevistadas. A fala de uma entrevistada é bastante representativa neste sentido, pois ressalta a dificuldade de entendimento das próprias ICTs da importância dos NITs:

Eu acho extremamente importante a criação dos NITs, porque, dentro do arcabouço da Lei de Inovação, precisava mesmo que tivesse uma estrutura diferenciada dentro das ICTs que pudesse fazer essa interface com a indústria. Agora, [...] só o fato de estar na Lei não é suficiente. Eu acho que a lei foi um grande indutor, mas a gente ainda não conseguiu atingir um nível no Brasil de que os NITs sejam efetivamente considerados necessários dentro da instituição (NIT5_2015)

$\mathrm{O}$ fato dos NITs precisarem de financiamento externo para sua estruturação e funcionamento confirma que o entendimento da importância dos NITs dentro das ICTs ainda não é completo. No entanto, não só dentro da ICT, mas também no governo, dentro dos Ministérios envolvidos (da Educação, da Ciência, Tecnologia e Inovação, e, principalmente, do Planejamento), que não abrem vagas de concurso para agentes de inovação nas ICTs públicas, e no Ministério de Ciência Tecnologia e Inovação, que parou de realizar editais de apoio aos NITs nas suas agências, FINEP e $\mathrm{CNPq}$, conforme mostrado neste artigo. Neste sentido, os NITs das ICTs privadas têm a vantagem de serem financiados pela própria instituição, quando esta resolve criá-lo. O fato de não haver obrigatoriedade nestes casos ajuda, pois a ICT que entende a importância do NIT vai criá-lo e apoiar seu funcionamento. No caso das ICTs públicas é diferente, pois não só os NITs são obrigatórios como estas instituições são extremamente heterogêneas. No âmbito estadual, a situação pode ser um pouco diferente. Na ICT pública estadual entrevistada, há, por exemplo, concurso com vagas para especialistas para o NIT. Isto, possivelmente, ocorre pelo número de ICTs ser menor, permitindo assim uma proximidade maior entre o governo e a gestão da ICT que consegue 
apresentar suas necessidades de forma mais fácil. As falas dos entrevistados, o primeiro de uma ICT federal e o segundo privada, corroboram as hipóteses levantadas acima.

[A Lei de Inovação] foi importante para criar... [...] Mas, junto com isso, tem que vir políticas e apoio para o NIT ser realmente o NIT. Não basta criar o NIT, ter três pessoas, e mesmo essas três pessoas, você não conseguir segurar no quadro, porque você não consegue contratar, você não consegue ter um concurso para a área. Fica muito no papel. Então, é importante, mas tem que funcionar de fato. Tem que ter infraestrutura, tem que ter políticas claras... (NIT4_2015)

O NIT aqui é todo mantido pela [ICT]. É claro que, quando tem editais, a gente sempre aplica (NIT5_2015).

Conforme dito acima, quanto mais antigo o NIT, melhor a estruturação. Isto também é verdade para o número de pessoas que nele trabalham. Apesar da média do Formict ser de oito pessoas trabalhando por NIT, sendo cerca de cinco servidores, quando olhados os dados dos NITs da pesquisa de campo percebe-se a imensa discrepância entre eles. Enquanto um NIT recém criado tem dois funcionários, os mais antigos têm 62 e $80^{8}$, conforme Tabela 2. Isto demonstra que a média apresentada no Formict não ajuda a se caracterizar os NITs propriamente, pois não reflete as grandes diferenças de pessoal ocupado que ocorre entre os NITs. Estes resultados não ajudam também a mostrar como a participação de bolsistas e estagiários é significativa. Nos NITs maiores, o número de bolsistas e estagiários chega a ser maior do que de servidores ou funcionários das ICTs.

Tabela 2: pessoal dos NITs por categoria (2015)
\begin{tabular}{c|c|c|c|c|c|}
\hline Total & $\mathbf{6 2}$ & $\mathbf{2}$ & $\mathbf{1 6}$ & $\mathbf{1 0}$ & $\mathbf{8 0}$ \\
\hline Funcionários & 28 & 2 & 9 & 6 & 16 \\
\hline Estagiários & 30 & 0 & 0 & 2 & \multirow{2}{*}{6} \\
\hline Bolsistas & 4 & 0 & 6 & 2 & \multirow{2}{*}{64} \\
\hline Terceirizados & 0 & 0 & 1 & 0 & \\
\hline
\end{tabular}

Fonte: Elaboração própria com base na pesquisa de campo

Esta característica representa um dos grandes obstáculos para o funcionamento dos NITs, que é a dificuldade de retenção de pessoal. Isto porque as bolsas disponíveis nos editais de financiamento das agências de fomento duram somente o período de execução do projeto (dois a três anos). Com o fim do recurso, e consequentemente da bolsa, o NIT perde aquele bolsista que foi treinado durante o período do projeto e somente após novo edital poderá contratar outra pessoa para fazer novamente o treinamento, e assim sucessivamente. Vale ressaltar que alguns dos serviços prestados pelos NITs, especialmente no que tange a proteção de conhecimento gerado nas ICTs, como a redação de patentes por exemplo, são extremamente técnicos, o que torna a alta rotatividade muito prejudicial para a continuidade da prestação desses serviços. Além disso, o fato de haver grande utilização de mão de obra sem vínculo empregatício (frequentemente bolsistas) faz com que ofertas de emprego no mercado de trabalho sejam mais atrativas e aumentem ainda mais a alternância de pessoal. Esta rotina leva a uma rotatividade muito grande no quadro de pessoal dos NITs, o que gera a perda de competências internas e de criação de rotinas eficientes. Uma entrevistada falou sobre a importância da capacitação do pessoal do NIT e o estabelecimento de processos para facilitar a interação.

Também é importante, por outro lado, que os NITs tenham pessoas qualificadas e que entendam também a realidade da empresa [...] porque não adianta nada você ter um NIT que não tem pessoa qualificada e que entenda e que você consiga falar. Cada vez mais você ter processos ágeis e dinâmicos na universidade para facilitar essa interação (NIT1_2015).

Apesar das limitações, os editais de financiamento são importantes fontes de recursos para os NITs, iniciais ou não; as bolsas permitem a ampliação do quadro de pessoal, o apoio a eventos e

\footnotetext{
${ }^{8}$ Neste caso, a entrevistada informou o número de funcionários do NIT e da incubadora que funcionam em conjunto.
} 
treinamento ajuda na capacitação da equipe, e os recursos de capital possibilitam a estruturação dos escritórios. Portanto, é prejudicial que Finep e CNPq não estejam mais abrindo editais para os NITs. Ultimamente, tais editais estão presentes somente nas FAPs, que acabam por oferecer recursos com valores mais baixos por projeto e, em geral, com maiores restrições para proporção de despesas de custeio e capital.

Apesar das dificuldades de estruturação, os NITs mostram-se extremamente importantes na gestão da PI das ICTs e importantes facilitadores da relação universidade-empresa. Comprova-se isso com o grande número de ICTs com políticas de inovação, ainda que tal exigência só tenha aparecido no novo Marco de CT\&I, com o aumento de pedidos de proteção intelectual e de transferências de tecnologia. Os resultados ainda são incipientes, mas é significativa a trajetória de crescimento.

Um dos grandes avanços aí que a gente teve após a Lei de Inovação foi justamente a criação dos NITs porque anteriormente as empresas não tinham um ponto de contato dentro da universidade, um órgão especializado na matéria que gerisse a política de inovação para estar tendo esse contato. Tudo isso o NIT proporcionou tanto para a comunidade acadêmica, quanto também para o meio empresarial (NIT1_2015).

Segundo um entrevistado, a própria Lei de Inovação não promove o licenciamento, só a proteção: "a Lei de Inovação só pensou na proteção, ela esqueceu de pensar no licenciamento também" (NIT3_2015). Uma importante mudança neste sentido implementada pelo Marco de CTI foi o fim da necessidade de edital público para o estabelecimento de contratos de licenciamento com exclusividade, o que pode facilitar a atração do interesse das empresas. No entanto, há morosidade na alteração das práticas da Administração Pública, especialmente no que tange a avaliação de documentos relativos à interação com empresas pelas Procuradorias (Federais e Estaduais), e os resultados dessa modificação legal podem demorar a ser verificados. No entanto, é importante notar ainda que o licenciamento não depende somente das ICTs, sua organização certamente é importante, mas ele depende fortemente também da demanda de empresas inovadoras, conforme já apresentado por Rapini (2007). O mesmo entrevistado de cima falou sobre a baixa cultura inovativa das empresas brasileiras: Entretanto, minha opinião, eu acho que apesar [dos editais para parcerias], [...] a questão [é] que essa cultura de inovação é incipiente nas empresas (NIT1_2015). Esta característica das empresas brasileiras é um grande obstáculo às parcerias com ICTs.

Outro obstáculo do relacionamento e da transferência de tecnologia ressaltado pelos entrevistados são as diferenças entre o mundo acadêmico e o empresarial, que ainda leva a grandes dificuldades apesar dos esforços dos NITs. Segundo um entrevistado, "Aquele empresário que consegue tirarlextrair, o que a universidade tem de melhor e a entender como ela funciona, ele tem êxito. Então essa questão do profissional capacitado e que já teve contato com o mundo acadêmico é essencial" (NIT1_2015). O entrevistado ressalta a importância de a empresa conhecer o funcionamento do ambiente acadêmico. Por outro lado, um segundo entrevistado destaca as dificuldades dos profissionais do NIT conhecerem o ambiente empresarial e o mercado: " $E$ a falta de pessoal técnico qualificado no NIT, a meu ver, esse é o principal. Sem esse básico, sem conhecer a tecnologia, a gente não tem como levar ela para o mercado" (NIT3_2015). Reforça ainda mais estas diferenças, a imaturidade das tecnologias geradas pelas ICTs, pois estas tecnologias em geral não estão submetidas às etapas de prova de conceito e prototipagem. Isso afasta as empresas que, como já dito acima, têm baixa cultura inovadora, o que em geral está ligado a uma aversão a risco que desestimula a aceitação de tecnologias imaturas. Falta uma política de fomento orientada para a maturação das tecnologias ofertadas pelas ICTs, ou um melhor relacionamento dessas com o ambiente industrial para captação das necessidades do setor produtivo nacional. 


\section{CONCLUSÃO}

A literatura internacional sobre a relação universidade-empresa mostra que a implementação, nas ICTs, de departamentos especializados na realização das parcerias são importantes promotores da aproximação entre o setor acadêmico e o empresarial. Conforme visto, no Brasil, buscou-se seguir esta tendência a partir do estabelecimento da obrigatoriedade dos NITs nas ICTs públicas, tendo várias ICTs privadas seguido a ação.

O relacionamento universidade-empresa entrou na pauta do governo juntamente com o tema da inovação como forma de viabilizar o desenvolvimento inovativo das empresas brasileiras a partir do forte sistema de C\&T estabelecido no país. Dessa forma, o tema entra nas políticas industriais e de CT\&I, conforme mostrado neste artigo, e na legislação de apoio a tais medidas. O aparato político e regulatório foi estabelecido, e recentemente atualizado, e foram apresentadas alternativas de financiamento, mas as dificuldades de estabelecimento e funcionamento dos NITs permanece.

É claro o crescimento em número de NITs e sua distribuição pelo país, e é relevante a ampliação de políticas de inovação das ICTs, mas é nítido também o baixo número de ICTs com depósitos de patente e contratos de transferência de tecnologia. Estes resultados demonstram que a Lei está sendo cumprida pelas ICTs ao criarem os seus NITs, mas os obstáculos ainda são enormes para que eles consigam desenvolver sua principal função - gestão da PI da ICT.

A origem dos obstáculos é variada, desde as características de investimento em inovação das empresas brasileiras até o funcionamento, regras e cultura das ICTs. Estudos estão sendo realizados pelos autores para avançar na identificação destas barreiras, mas os dados apresentados neste artigo dos editais de financiamento e apoio aos NITs já permitem algumas conclusões. Primeiro, formam muito poucos (três) e espaçados no tempo (2006, 2008 e 2013), os editais em âmbito federal. A partir de 2012 (sete anos após a regulamentação da Lei de Inovação), ganha frequência os editais no âmbito estadual (FAPERJ e FAPEMIG), aproximando-se da ação da FAPESP desde 2000. Porém, em muitos casos, os valores por projetos eram bastante inferiores aos das chamadas em âmbito federal, reduzindo sua capacidade de resultados dada a pulverização de recursos. É frequente a presença das bolsas para contratação de pessoal, que apresenta um lado positivo pela possibilidade de complementação da equipe fixa dos NITs (que costuma ser pequena), mas tem também um lado negativo, pois gera muita rotatividade de pessoal e perda frequente de capacitação nos NITs. Em síntese, falta apoio financeiro para o estabelecimento, funcionamento e capacitação de pessoal dos NITs.

Em termos de marco regulatório, após 10 anos, algumas mudanças mais significativas foram estabelecidas no sentido de facilitar as parcerias através da redução da insegurança jurídica e ampliação das funções do NIT. A Emenda Constitucional 85 pôs fim à incompatibilidade entre a Lei de Inovação e a Constituição Federal, que era um grande entrave para a chancela, pelos procuradores federais lotados nas ICTs, dos contratos de parceria, reduzindo a insegurança jurídica no estabelecimento da relação universidade-empresa. Ela permite assim avanços no Marco de CT\&I, que também amplia as funções do NIT para além da gestão da PI, incluindo a promoção da cultura empreendedora dentro das ICTs, outro fator bem positivo. Isto porque para se mudar o funcionamento da ICT e suas regras, é preciso mudar seu entendimento sobre a inovação, sobre o papel da universidade, sobre a questão empreendedora. No entanto, os dados secundários ainda não permitem a identificação de seus efeitos.

Certamente, os obstáculos ao relacionamento universidade-empresa vão muito além da atuação dos NITs. No entanto, é importante que as políticas e ações do governo para este fim atentem para o bom estabelecimento, estruturação e funcionamento dos NITs, pois eles podem ser atores de mudança dentro das ICTs e importantes facilitadores das parcerias, na divulgação da pesquisa das ICTs para a sociedade e na aproximação das empresas às ICTs. 


\section{REFERÊNCIAS}

ABDI, Plano Brasil Maior - Balanço Executivo 2 anos. Disponível em: http://www.abdi.com.br. Acesso em: 13 de set. 2016.

. Estratégia Nacional de Ciência, Tecnologia e Inovação 2012 - 2015. Brasília: MCTI, 2011

. Política de Desenvolvimento Produtivo. Brasília: MDIC, 2008.

Relatório Formict 2006 a 2014: Política de propriedade intelectual das instituições científicas e tecnológicas do Brasil. Brasília: MCTI, 2007 a 2015.

ARCHILA, D. Condicionantes do potencial de exploração comercial da patente: a implantação de um sistema de oferta pública de tecnologia na CNEN. Rio de Janeiro: PPED/IE/UFRJ (Dissertação de Mestrado)

BOZEMAN, B, et al., (2014) The Evolving State-of-the-Art in Technology Transfer Research: Revisiting the Contingent Effectiveness Model, Research Policy, vol 44, "n 1", pp. 24-49.

CASTRO. B. S, SOUZA, G. C, (2012) O papel dos Núcleos de Inovação Tecnológica (NITs) nas universidades brasileiras, Liinc em Revista, v.8, “n¹”, pp. 125-140.

D'ESTE, P., PATEL, P., 2007. University-industry linkages in the UK: what are the factors underlying the variety of interactions with industry? Research Policy 36, 1295-1313.

DE FUENTES, C., \& DUTRÉNIT, G. (2012). Best channels of academia-industry interaction for long-term benefit. Research Policy, 41(9), 1666-1682.

ETZKOWITZ, H., \& LEYDESDORFF, L. (2000). The dynamics of innovation : from National Systems and ““ Mode 2 "” to a Triple Helix of university - industry - government relations, Research Policy, v29, no 2, pp.109-123.

LIEW, M.S, et al., (2012) Strategic and Tactical Approaches on University - Industry Collaboration. Procedia - Social and Behavioral Sciences, v. 56, pp. 405-409.

LUNDVALL, B.-Å. The university in the learning economy. DRUID Working Paper, n. 6, 2002.

MCTI - Ministério da Ciência, Tecnologia e Inovação. Ciência, Tecnologia e Inovação para o Desenvolvimento Nacional - Plano de Ação 2007-2010. Brasília: MCTI, 2007

MDIC - Ministério do Desenvolvimento, Indústria e Comércio Exterior. Diretrizes de Política Industrial, Tecnológica e de Comércio Exterior. Brasília: MDIC, 2003.

MOWERY, D, SAMPAT, B, (2005) Universities in National Innovation Systems. In: FARGERBERG, J. et al.(Ed.). The Oxford handbook of innovation. New York: Oxford Universtiy Press.

MUSCIO, A. (2010). What drives the university use of technology transfer offices? Evidence from Italy. Journal of Technology Transfer, 35, 181-202.

O’KANE, C., MANGEMATIN, V., GEOGHEGAN, W., FITZGERALD, C., KANE, C., FITZGERALD, C. (2015). University technology transfer offices : The search for identity to build legitimacy. Research Policy, 44(2), $421-437$.

ORSI, F, CORIAT, B, (2006) The new role and status of Intellectual Property Rights in contemporary capitalism, Competition \& Change, v. 10, " $\mathrm{n}$ "2", 162-179.

PARANHOS, J, (2012), Interação entre empresas e instituições de ciência e tecnologia: o caso do sistema farmacêutico de inovação brasileiro. Rio de Janeiro: EdUERJ.

RAPINI, M, (2007) Interação Universidade-Empresa no Brasil: Evidências do Diretório dos Grupos de Pesquisa do CNPq, Estudos Econômicos, v. 37, “n¹”, pp. 211-233.

ROSENBERG, N., NELSON, R., 1994. American universities and technical advance in industry. Research Policy (23), 323-348. 
SIEGEL, D. S., VEUGELERS, R., \& WRIGHT, M. (2007). Technology transfer offices and commercialization of university intellectual property: performance and policy implications. Oxford Review of Economic Policy, 23(4), 640660.

SIEGEL, D. S., WALDMAN, D., \& LINK, A. (2003). Assessing the impact of organizational practices on the relative productivity of university technology transfer offices: An exploratory study. Research Policy, 32, 27-48.

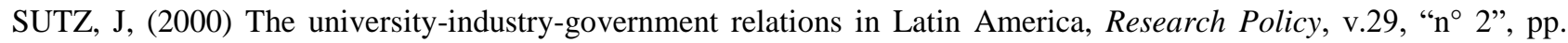
279-290.

WELSH, R., GLENNA, L., LACY, W., BISCOTTI, D., 2008. Close enough but not too far: assessing the effects of university-industry research relationships and the rise of academic capitalism. Research Policy 37, 1854-1864

YIN, R, (2005) Estudo de caso: planejamento e métodos. Porto Alegre: Bookman. (3ª. Ed.) 